\section{COVID-19 e Cirurgias Urgentes: O Que Mudou?}

\section{COVID-19 and Urgent Surgeries: What Has Changed?}

Palavras-chave: Coronavírus; COVID-19; Procedimentos Cirúrgicos Operatórios; Tempo para o Tratamento

Keywords: Coronavirus; COVID-19; Surgical Procedures, Operative; Time-to-Treatment

\section{Caro Editor,}

Lemos com muito interesse o artigo Excess Mortality Estimation During the COVID-19 Pandemic: Preliminary Data from Portugal, ${ }^{1}$ publicado na vossa revista. O Serviço de Anestesiologia do Centro Hospitalar Universitário Lisboa Norte encontra-se em fase de interpretação de dados relacionados com a atividade anestésica para cirurgia urgente realizada na nossa instituição entre os dias 1 de março e 30 de abril de 2020.

Os dados preliminares indicam uma redução de $31,2 \%$ da atividade cirúrgica urgente em março de 2020 quando comparado com o mês homólogo de 2019 e de $18,3 \%$ em abril de 2020 em comparação com o mesmo mês em 2019. Quando a comparação é feita com os meses de julho e agosto de 2019, que se poderiam assemelhar à realidade da pandemia que vivenciamos, ${ }^{1}$ e que vai ao encontro do artigo referenciado, a redução é de $34,7 \%$ e $29,3 \%$, respetivamente. No entanto, nesta altura do ano há geralmente um aumento do número de cirurgias urgentes na nossa instituição, atribuído às transferências de doentes de outros hospitais com menor capacidade de recursos humanos. Poderá, de facto, ter havido menos intervenções cirúrgicas devido ao confinamento? Podemos especular que se verificaram menos situações de trauma ou menos abordagens cirúrgicas de complicações da cirurgia eletiva? Poderá ter havido menos cirurgias urgentes no âmbito da Urologia, Cirurgia Geral ou Vascular em plena pandemia? Podemos dizer que sim. Estarão os doentes a recorrer a estabelecimentos hospitalares privados? Estarão os hospitais a transferir menos? Não temos tanta certeza.

Poderá esta redução percentual no número de cirurgias urgentes estar associada a uma maior mortalidade global? Embora estes dados sejam ainda preliminares, e com inúmeras variáveis que teremos que aprofundar, verificámos uma redução importante no número de cirurgias urgentes, situação que não seria expectável, e que poderá ir ao encontro do aumento da mortalidade verificada no artigo publicado.

\title{
REFERÊNCIAS
}

1. Nogueira PJ, Nobre MA, Nicola PJ, Furtado C, Carneiro AV. Excess mortality estimation during the COVID-19 pandemic: preliminary data

from Portugal. Acta Med Port. 2020 (in press). doi.org/10.20344/ amp.13928

Joana RIBEIRO ${ }^{1}$, Patrícia NAVE¹, Ana PAULINO1 ${ }^{1}$, Lucindo ORMONDE ${ }^{1}$

1. Serviço de Anestesiologia. Centro Hospitalar Universitário Lisboa Norte. Lisboa. Portugal. Autor correspondente: Joana Ribeiro. joribeiro_91@hotmail.com

Recebido: 13 de maio de 2020 - Aceite: 14 de maio de 2020 | Copyright $\odot$ Ordem dos Médicos 2020 https://doi.org/10.20344/amp.14126
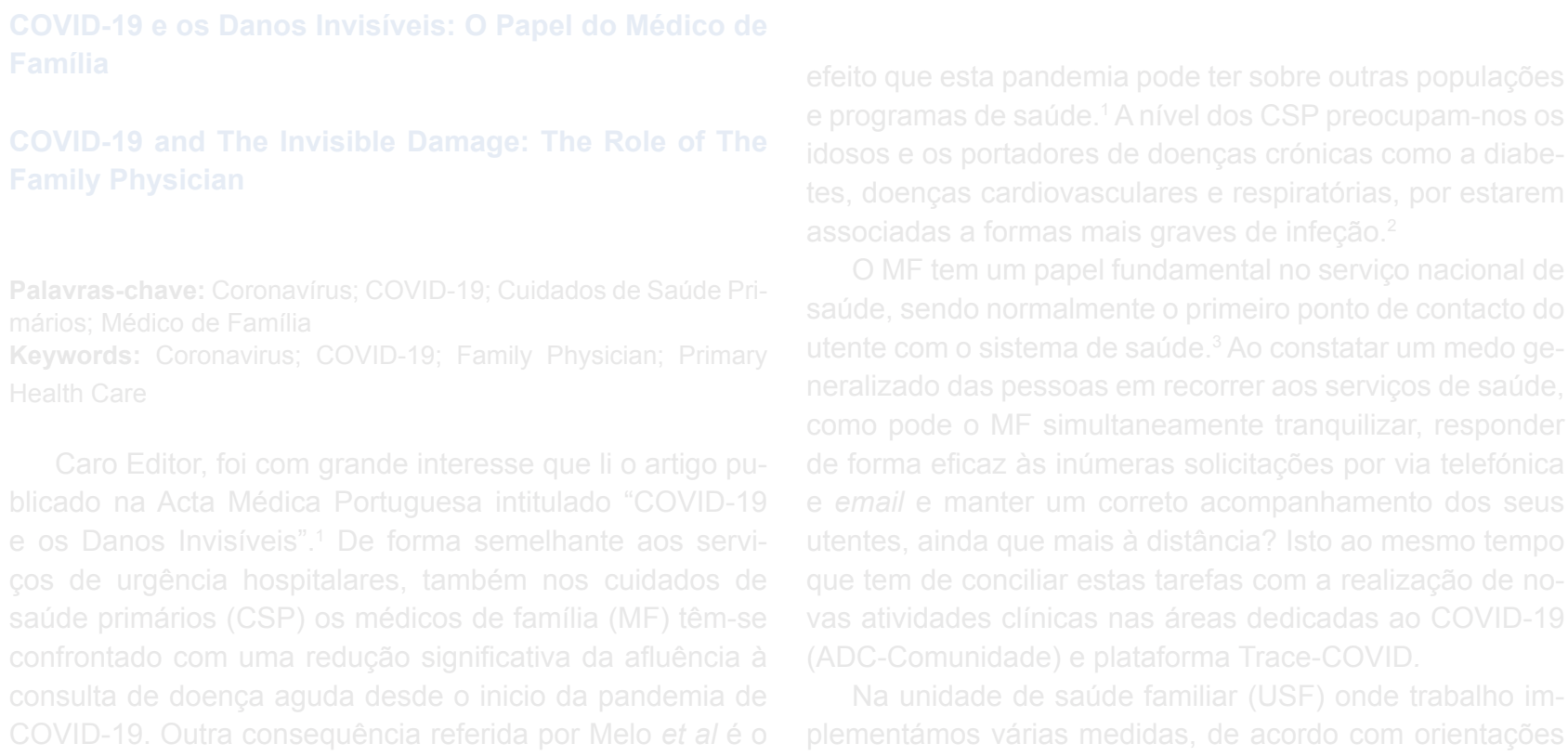